\title{
Integrative Approach to Multidisciplinary Training in Physiology and Biomedical Engineering
}

Rajajeyakumar $\mathbf{M}^{1^{*}}$, Bhattacharjee $\mathbf{M}^{2}$, Vivek Kumar Sharma ${ }^{3}$ and Janitha Alagarsamy ${ }^{4}$

${ }_{1}^{1}$ Assistant Professor, Department of Physiology, Chennai Medical College Hospital and Research Centre, Irungalur, Trichy-621105, Tamilnadu, India ${ }^{2}$ Assistant Professor, Department of Physiology 2, Vardhman Mahavir Medical College and Safdarjung Hospital, Delhi, India

${ }^{3}$ Additional Professor, Department of Physiology, JIPMER, Pondicherry-605006, India

${ }^{4}$ Senior Medical Officer, Bharat Heavy Electricals Limited, Trichy-620014, Tamilnadu, India

\section{Introduction}

Physiology is at the crossroads of the basic sciences and applied sciences, making it a suitable context for the interdisciplinary education of biomedical scientists and engineers. However, an increased importance on physiology education is arising in the rapidly emerging biomedical engineering field. At the same time, both biosciences and biomedical engineering programs are being encouraged to engage undergraduate students in interdisciplinary research. The Physiology and Biomedical Engineering, from basic research to clinical implementation, are addressed through the collaboration of faculty and students from different backgrounds, including biomedical, electrical, mechanical engineering, biology, physics, physiology and medicine. This provides a basic academic platform and a dynamic learning environment that emphasizes problem solving, communication skills and critical thinking. This also helpful to build up the skills necessary to be successful for research and future careers [1].

Collaboration with faculty from a wide variety of disciplines, as well as with clinicians, provides support and guidance for students. They are able to work closely with world-renowned experts in their fields on a daily basis and gain skills and professional training. Students also have access to the strong research infrastructure including a wide variety of core facilities and experts in biostatistics and bioinformatics and develop a platform to apply engineering knowledge to health care and medical research.

\section{Recent Research Topics}

Research in the Department of Bioengineering is focused on solving medically relevant problems. The clinical departments in the hospital help in testing and evaluating the products. Most problems are defined in association with one or more departments in the hospital or the medical college. Faculties from these departments are involved in the research through the period of development [2].

Some of the topics on which research is being undertaken are

- Physiological Signal Recording and Processing Precision Grip for Sensorimotor Qualification Hardware and Software for Gait Analysis

\section{- Magnetic Stimulator for Evaluation of Conduction in CNS}

Modern medicine has given rise to the development of a wide range of novel engineering solutions to clinical problems. As a result of this increased collaboration between engineers and doctors, the new discipline of Biomedical Engineering has developed. Students who follow this can look forward to exciting and rewarding careers in Medical Device manufacture, Biomedical Engineering research,
Implant Design, Surgical Instrument Design, as well as opportunities in Design and Biomedical Materials.

\section{Areas of Emphasis are Available to Students to Biomedical Engineering and Physiology}

The research covers areas from physiological modelling to noninvasive measurements of various physiological parameters. In medical ultrasound, bio-optics, bio-acoustics our main application areas are in the cardiovascular area. In ultrasound development of ultrasound contrast, methods to measure blood perfusion in the heart muscle are performed. Simulation and in-vitro modelling are used. Bio-optical research is performed on photoplethysmography, the origin of this signal and how this signal can be related to blood flow. Furthermore, absorption spectroscopy is used to study the chemical content in fluids and is applied to optimizing the dialysis process. A concept in the bioacoustic research is the intelligent stethoscope where physiologically relevant information is extracted from the signal. Intelligent sensors in home and primary health care are one main area of application strengths in basic and translational research includes monitoring single biomolecule function in real time.

\section{Need for Curriculum Development}

The Biomedical Engineering and Physiology curriculum is designed to provide students with the knowledge and skills necessary to be successful in their research and future careers. All Biomedical Engineering and Physiology post graduate students complete the core curriculum, which provides students with a firm foundation in biomedical engineering and physiology concepts.

The core curriculum includes courses on many topics, including mathematics, physiology, imaging, biomechanics and biomedical engineering. Students also take advanced courses directly related to

*Corresponding author: Rajajeyakumar M, Assistant Professor, Department of Physiology, Chennai Medical College Hospital \& Research Centre (SRM Group), Irungalur, Trichy, Tamilnadu - 621105, India, Tel: 09751382650; E-mail: rajakumar60@gmail.com

Received: November 21, 2014; Accepted: November 22, 2014; Published: January 01, 2015

Citation: Rajajeyakumar M, Bhattacharjee M, Sharma VK, Alagarsamy $J$ (2015) Integrative Approach to Multidisciplinary Training in Physiology and Biomedical Engineering. J Bioengineer \& Biomedical Sci 5: 136. doi:10.4172/2155-9538.1000136

Copyright: ( 2015 Rajajeyakumar M, et al. This is an open-access article distributed under the terms of the Creative Commons Attribution License, which permits unrestricted use, distribution, and reproduction in any medium, provided the original author and source are credited. 
their chosen research projects. The advanced curriculum is tailored to meet the needs of each individual student.

\section{Hands on Training}

Training is chiefly through involvement in research projects, in conjunction with the faculty. Seminars are held to discuss the progress of research and trainees are expected to present their research results at national meetings.

Signal analysis, including muscles (EMG), brain (EEG), eyes (EOG) \& Respiration Cardiovascular and autonomic nervous system analysis.

- Microscopy, medical imaging and image processing.

- Nano probes such as quantum dots to study cell function.

- $\quad$ Computers in medical education. Biomedical Ethics.

The biomedical engineering graduates who have had hands-on physiology laboratory experiences as part of their studies will have addressed the problems associated with the interaction between living and nonliving material as required by the accreditation criteria.

\section{Discussion and Conclusion}

Interdisciplinary physiology laboratory activities were developed by a multidisciplinary team of faculty members from Basic Medical Sciences, the Weldon School of Biomedical Engineering, and the Department of Biological Sciences at Purdue University. The laboratory activities were developed for a new team-based course, "Measurement and Design in Physiology Systems," where both engineering and science disciplinary perspectives were presented to mixed discipline teams of students. Teams of biology and biomedical engineering students populated the pilot course to experiment, design systems, and solve problems related to physiology. As far as we know, a multidisciplinary undergraduate physiology laboratory course did not previously exist. The physiology laboratory provided an environment where the similar as well as unique disciplinary desired outcomes were reached through slight modifications of physiology activities to create interdisciplinary physiology laboratory experiences

It is likely that teams of engineers and basic scientists working together will continue to advance emerging frontiers in biomedical research. Solutions to many societal problems will lie at the interface between the disciplines, and it will be up to current faculty to provide interdisciplinary instructional experiences where the different problem-solving approaches unique to disciplines are recognized and appreciated. Physiology is uniquely poised at the interface of biology and engineering as a common field for both disciplines to foster the skills necessary to function as part of a multidisciplinary team. (3) Meanwhile, the Engineer of 2020: Visions of Engineering in the New Century by the National Academy of Engineering claimed that "Exciting breakthroughs in our understanding of human physiology have been among the most captivating topics of public discussion over the past several decades." According to the Engineer of 2020.

\section{Recommendation}

Studies have shown that undergraduate students actively engaged in research have a better understanding of how scientific knowledge is built, improve their understanding of scientific principles, and assimilate new knowledge more effectively with active, inquiry-based collaborative learning and creative thinking $[3,4]$.

Collaboration is taking place both on a national and international level in close collaboration with the biomedical engineering industry and hospital clinics. There are four research divisions: Biomedical Instrumentation, Biomedical Modelling and Simulation, Physiological Measurements and Medical Informatics. Innovations that further these goals will benefit science, the workforce, future innovation, and the quality of physiology instruction.

\section{Acknowledgments}

The authors thank Dr. Rajendren for discussions about encounters between undergraduate bioscience and biomedical engineering students and the benefits of interdisciplinary teamwork. The authors also thank Dr. Nachal Annamalai for helpful comments about biomedical engineering approaches to science and suggested references.

\section{References}

1. Clase KL, Hein PW, Pelaez NJ (2008) Demand for interdisciplinary laboratories for physiology research by undergraduate students in biosciences and biomedical engineering. Adv Physiol Educ 32: 256-260.

2. ABET (2007) Accreditation Board for Engineering and Technology Engineering Accreditation Commission. Criteria for Accrediting Engineering Programs. Baltimore, Maryland.

3. National Academy of Engineering (2004) The Engineer of 2020: Visions of Engineering in the New Century. The National Academies Press, Washington DC, USA.

4. Silverthorn DU (2003) Restoring physiology to the undergraduate biology curriculum: a call for action. Adv Physiol Educ 27: 91-96. 